\section{Sun setting on water quality exemptions}

$\mathrm{T}$ races of diazinon are in the Sacramento River. Chlorpyrifos has been discovered between the banks of the San Joaquin. Federal officials say tiny amounts of these and other pollutants impair hundreds of California rivers, creeks, streams and sloughs.

The environmental group DeltaKeepers has filed a series of petitions and lawsuits to require cleanup of California surface waters. "There are 5 million acre-feet of tail water coming from agricultural fields in California, transported through 6,000 to 15,000 miles of drainage channels to an unknown number of outfalls, at unknown locations with unknown pollutants," DeltaKeepers executive director Bill Jennings says. "We need to identify these."

Farmers are also concerned, says John Garner, a Glenn County farmer who chairs the California Farm Bureau Federation's water advisory committee.

"Our livelihood depends on being ecologically balanced," Garner says. "Farmers are problemsolvers. We want to sit down with people involved in the process, come up with a workable solution, do it and get on with farming."

The federal Clean Water Act of 1972 set the stage for the current controversy. The law requires states to evaluate surface waters in order to determine where pollutants are adversely affect-

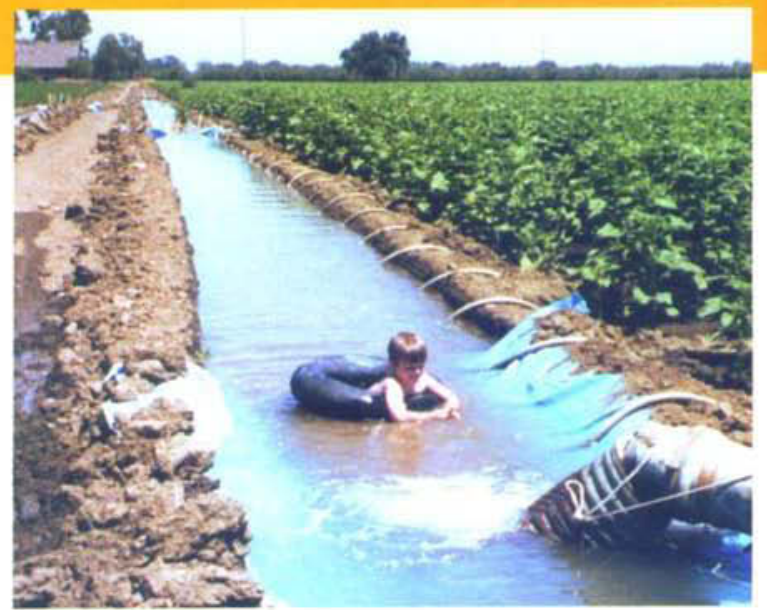

California agriculture's exemption from Clean Water Act provisions is set to expire in 2003. Growers may be required to develop plans for limiting pollution of natural waterways to protect beneficial uses such as fishing, swimming and wildlife habitat. Four-year-old Eugene Long plays in source water for sunflower irrigation on his family's Yolo County farm.

ing beneficial uses, such as fishing, swimming and wildlife habitat. It also requires that sources of pollutants be identified and then limited. (Total maximum daily load [TMDL] limits must be established for each pertinent pollutant in regulated waterways.) As a result, California compiled a list of 509 impaired waterways and began efforts to clean them up.

The California Water Code, adopted in 1982, also requires those who discharge wastewater into California's streams and rivers to submit a report to the Regional Water Quality Control Board. Industries and municipalities have been submitting the waste discharge reports, but all

\title{
Letters
}

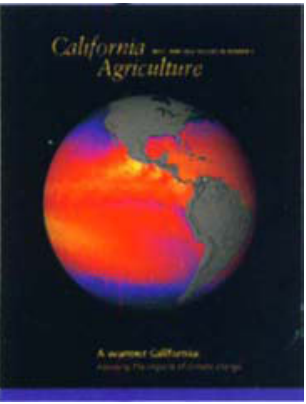

\section{Climate debate heats up}

Too much space was spent on global warming in the May-June 2002 issue. The editorial points out how little we know about global climate change. The authors also say that global climate change will occur in longer periods than 50 to 100 years. Faced with that uncertainty they propose we should "emphasize measures that reduce the apparent driving forces behind global climate change." The "scientists" pushing the global warming idea never seem to consider factors such as increased output of energy from the sun or subtle changes in the earth's orbit. They concentrate on activities of man as the driving force. The earth has been much colder (glaciers) and warmer than it currently is. Industrial mankind wasn't around for those changes. I suggest we recognize that global climate change occurs but science hasn't yet discovered all of the possible causes and certainly can't interpret the interactions of all the possible causes.

Allan L. James, Mid Valley Ag

Linden, California
Bryan Weare ("Global climate change will affect air, water in California," Cal Ag 56(3):89-96) responds.

The reader states that scientists "never seem to consider factors such as increased output of energy from the sun or subtle changes in the earth's orbit." This is incorrect. The Hadley model, as well as many others, has taken into account our best understanding of solar output changes over the time frame of decades to centuries. Solar orbital changes work only on much longer times of many thousands of years.

Second, the reader notes that the earth's climate has been colder and warmer than it currently is, and that these changes occurred long before industrial mankind. Nothing in the review article suggests that climate change does not exist on longer glacial time scales. However, human activity is apparently leading to relatively large changes in climate at a rate much faster than has been seen in the recent geological past or is likely without human intervention. Of course climate is always changing. The important policy factor is whether or not the rate of change is exceeding our ability to accommodate it without large disruptions in our social and economic institutions. 
nine of California's regional boards adopted waivers for the return of agricultural irrigation water to surface streams and rivers.

"Ever since then, and before that, farmers have been discharging irrigation return flows without a whole lot of oversight," says Rudy Schnagl, chief of the agriculture unit of the Central Valley Regional Water Quality Control Board. "The waivers are conditional. They say the discharger has to make sure discharge doesn't cause toxicity to fish and wildlife and that sediment is controlled to meet turbidity requirements in the receiving water. The problem is, we don't have enough staff to go out and actively enforce the waivers."

Legislation passed in 1999 - Senate Bill 390 (Alpert-San Diego) - requires all waivers to sunset on Jan. 1, 2003. Under the new provisions, the water boards must review waivers at least once every 5 years and ensure compliance before granting a renewal.

"We're scrambling to adjust our program to meet these new provisions," Schnagl says. "We will take an interim plan to the board this fall and initiate environmental impact reports to conduct a thorough review of the options the board has for a long-term policy."

If the waivers are not renewed, all farmers will be obligated to submit reports of waste discharges, which detail where the wastewater is going and what it contains.

"We're facing tens of thousands of those kinds of reports," Schnagl says. "We have 7 million acres of irrigated agriculture in the Central Valley. The challenge is focusing on those that cause problems while minimizing the burden on those that don't."

The type and amount of pollutants potentially found in farm runoff depend on irrigation methods, rainfall amounts, crops, soil types, pesticides, fertilizers, management practices and other factors. Irrigation return waters can carry pesticide residues, sediment, nutrients, salt and trace elements, such as selenium. The temperature of agricultural runoff can also have an impact on natural waterways.

Jennings of DeltaKeepers says many farmers are already implementing management practices that prevent the flow of polluted water into streams and rivers, such as installing irrigation return systems and following integrated pest management (IPM) practices. He sees the forthcoming changes as an opportunity to identify farms that are sources of pollution.

Theresa Dunham, director of water resources for the California Farm Bureau Federation, would like to see the waivers renewed for a 3- to 4-year period so the regional boards can monitor watersheds and determine where the problems lie.

"Until we do some baseline monitoring to see where problems are occurring and pinpoint how to address the problems, reporting efforts will be money down the drain," Dunham says. "I think farmers need to be given the ability and the information to determine for themselves how to operate their farms to manage water quality."

\section{Water quality research}

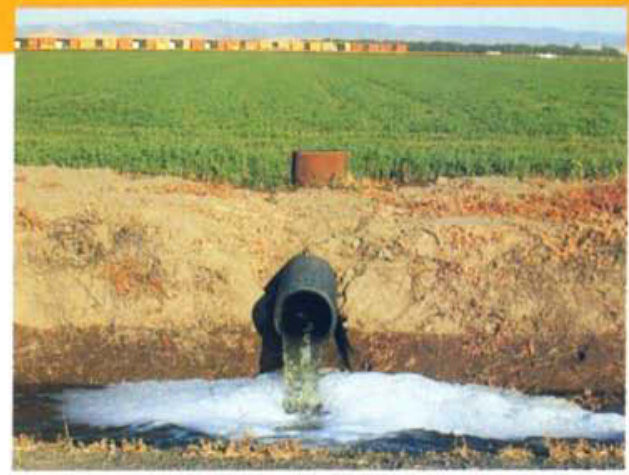

Irrigation tail water, above, may contain pollutants such as pesticide residues, sediment, nutrients and salt. Research by UC scientists describes how insecticide choice in alfalfa may affect aquatic life.

Offering this infor-

mation to farmers became one of UC Cooperative Extension farm advisor Rachael Long's goals when she learned that chlorpyrifos was found in California rivers and streams at levels toxic to water organisms (see p. 163).

"Many farmers were interested in cooperating with me," Long says. "They weren't aware of the water quality issues and that pesticides were being found in natural waterways."

Funded by the State Water Resources Control Board, Long and colleagues found that the pyrethroids they tested were less likely to run off alfalfa fields than the more commonly used organophosphate pesticides. Some pyrethroids do not dissolve readily in water but instead bind to soil particles. Organophosphates are partially soluble in water, making it easier for them to leave the farm in runoff. In 1999, Long compared the effectiveness of pesticides belonging to the two classes of chemicals on Egyptian alfalfa weevil, a major alfalfa pest.

After the field trials began, chlorpyrifos use decreased significantly in Solano County, Long says. In 1998, almost 12,000 pounds of chlorpyrifos were sprayed on 19,000 acres of alfalfa. In 2000, the amount was less than 3,000 pounds. In Yolo County, almost 14,000 pounds of chlorpyrifos were sprayed on 25,000 alfalfa acres in 1998; in 2000 , use dropped to 7,000 pounds.

" $\mathrm{I}$ ' $\mathrm{m}$ interested in being proactive and my experience shows that it works," Long says. "I'd like to continue looking for alternatives to stop water quality problems from getting worse and avoid more regulations coming down on agriculture."

Research and extension efforts to enhance water quality will continue to be a priority for UC scientists, says Bill Frost, UC natural resources program leader. "Our water quality workgroup is coordinating efforts in crop and orchard production, and in the livestock and timber industries to find ways growers and ranchers can continue economically viable practices while maintaining water quality standards." 